\title{
Compartmental chest wall volume changes during volitional normocapnic hyperpnoea
}

\author{
Illi, Sabine K ; Hostettler, Stefanie ; Mohler, Evelyn ; Aliverti, Andrea ; Spengler, Christina M
}

\begin{abstract}
During increased ventilation, inspiratory rib cage muscles have been suggested to take over part of diaphragmatic work after the diaphragm fatigues. We investigated the extent to which this proposed change in muscle recruitment is associated with changes in the relative contribution of chest wall compartments to tidal volume $(\mathrm{V}(\mathrm{T}))$. Thirteen healthy subjects performed $1 \mathrm{~h}$ of fatiguing normocapnic hyperpnoea. Chest wall volumes were assessed by optoelectronic plethysmography. While breathing frequency increased $(43 \pm 3$ to $56 \pm 5$ breaths $\min (-1), \mathrm{p}=0.006)$ and $\mathrm{V}(\mathrm{T})$ decreased during normocapnic hyperpnoea $(2.6 \pm 0.2$ to $1.9 \pm 0.11, \mathrm{p}<0.001)$, the relative contribution of chest wall compartments to $\mathrm{V}(\mathrm{T})$ remained unchanged (pulmonary rib cage: $48 \pm 9$ versus $51 \pm 14 \%$; abdominal rib cage: $24 \pm 4$ versus $23 \pm 9 \%$; abdomen: $28 \pm 8$ versus $26 \pm 9 \%$; all $\mathrm{p}>0.05$ ). In conclusion, fatiguing respiratory work is not associated with a change in compartmental contribution to $\mathrm{V}(\mathrm{T})$, even in the presence of a change in breathing pattern.
\end{abstract}

DOI: https://doi.org/10.1016/j.resp.2011.05.007

Posted at the Zurich Open Repository and Archive, University of Zurich

ZORA URL: https://doi.org/10.5167/uzh-76632

Journal Article

Accepted Version

Originally published at:

Illi, Sabine K; Hostettler, Stefanie; Mohler, Evelyn; Aliverti, Andrea; Spengler, Christina M (2011). Compartmental chest wall volume changes during volitional normocapnic hyperpnoea. Respiratory Physiology Neurobiology, 177(3):294-300.

DOI: https://doi.org/10.1016/j.resp.2011.05.007 


\section{Compartmental chest wall volume changes during volitional normocapnic hyperpnoea}

Sabine K. Illi ${ }^{\mathrm{a}, \mathrm{b}}$, Stefanie Hostettler ${ }^{\mathrm{a}, \mathrm{b}, \mathrm{c}}$, Evelyn Mohler ${ }^{\mathrm{a}}$, Andrea Aliverti ${ }^{\mathrm{d}}$, Christina M.

Spengler ${ }^{\mathrm{a}, \mathrm{b}, *}$

${ }^{a}$ Exercise Physiology, Institute of Human Movement Sciences, ETH Zurich,

Winterthurerstrasse 190, 8057 Zurich, Switzerland

${ }^{b}$ Institute of Physiology and Zurich Center for Integrative Human Physiology (ZIHP),

University of Zurich, Winterthurerstrasse 190, 8057 Zurich, Switzerland

${ }^{c}$ Swiss Paraplegic Research, Guido A. Zäch Strasse 4, 6207 Nottwil, Switzerland

${ }^{d}$ TBM Lab, Dipartimento di Bioingegneria, Politecnico di Milano, P.zza L. da Vinci 32,20133

Milano, Italy

*Corresponding author at:

University and ETH Zurich

Exercise Physiology

Institute of Human Movement Sciences

Winterthurerstrasse 190

8057 Zurich, Switzerland

Tel: $\quad+41446355007$

Fax: $\quad+41446356814$

E-mail addresses:

sabine.illi@physiol.biol.ethz.ch (S.K. Illi), stefanie.hostettler@ physiol.biol.ethz.ch (S.

Hostettler), e.mohler@unibas.ch (E. Mohler), andrea.aliverti@polimi.it (A. Aliverti), spengler@ethz.ch (C.M. Spengler) 


\begin{abstract}
During increased ventilation, inspiratory rib cage muscles have been suggested to take over part of diaphragmatic work after the diaphragm fatigues. We investigated the extent to which this proposed change in muscle recruitment is associated with changes in the relative contribution of chest wall compartments to tidal volume $\left(\mathrm{V}_{\mathrm{T}}\right)$. Thirteen healthy subjects performed $1 \mathrm{~h}$ of fatiguing normocapnic hyperpnoea. Chest wall volumes were assessed by optoelectronic plethysmography. While breathing frequency increased ( $43 \pm 3$ to $56 \pm 5$ breaths $\left.\cdot \min ^{-1}, \mathrm{p}=0.006\right)$ and $\mathrm{V}_{\mathrm{T}}$ decreased during normocapnic hyperpnoea $(2.6 \pm 0.2$ to $1.9 \pm 0.11, \mathrm{p}<0.001)$, the relative contribution of chest wall compartments to $\mathrm{V}_{\mathrm{T}}$ remained unchanged (pulmonary rib cage: $48 \pm 9$ versus $51 \pm 14 \%$; abdominal rib cage: $24 \pm 4$ versus $23 \pm 9 \%$; abdomen: $28 \pm 8$ versus $26 \pm 9 \%$; all $\mathrm{p}>0.05)$. In conclusion, fatiguing respiratory work is not associated with a change in compartmental contribution to $\mathrm{V}_{\mathrm{T}}$, even in the presence of a change in breathing pattern.
\end{abstract}

Keywords: breathing pattern, respiratory control, respiratory muscle fatigue, optoelectronic plethysmography 


\section{Introduction}

While respiratory muscle training has been shown to improve endurance performance, the mechanisms leading to this ergogenic effect are not yet fully understood (Gigliotti et al., 2006; McConnell and Romer, 2004; Sheel, 2002). Delaying the development of respiratory muscle fatigue seems to play an important role in improving endurance performance (Romer et al., 2002; Verges et al., 2007), because respiratory muscle fatigue has been shown to elicit a so called metaboreflex resulting in vasoconstriction and decreased perfusion of exercising limbs (Harms et al., 1997; St Croix et al., 2000), thereby compromising performance. Slowing the development of respiratory muscle fatigue with respiratory muscle training seems to be associated with a delay in the development of rapid shallow breathing (Romer et al., 2002; Verges et al., 2008; Wylegala et al., 2007), which in turn could be linked to a change in respiratory muscle action.

Electromyography is commonly used to assess muscle activity. However, the large number of muscles involved in breathing and their anatomical location makes the use of electromyography difficult. Alternatively, optoelectronic plethysmography (OEP) can be used to assess the action of the different respiratory muscle groups. OEP is a motion analysis system to assess changes in chest wall volumes non-invasively (Cala et al., 1996; Ferrigno et al., 1994). It allows the chest wall volume ( $\mathrm{Vcw}$ ) to be partitioned into three different compartments based on the two-compartment model of the rib cage by Ward et al. (Ward et al., 1992). The compartmental volume changes are affected by the specific mechanical properties of this compartment including the muscles acting on it, the pressures it is exposed to, and its compliance. Changes in volume of the pulmonary rib cage $(\Delta \operatorname{Vrc}, p)$ reflect the action of the inspiratory and expiratory rib cage muscles, changes in volume of the abdominal rib cage $(\Delta V r c, a)$ reflect the action of the diaphragm and abdominal muscles, and abdominal 
volume changes $(\Delta \mathrm{Vab})$ also reflect the action of both the diaphragm and the abdominal muscles.

Investigations of chest wall volume changes using OEP during exercise- (Aliverti et al., 1997; Duranti et al., 2004; Sanna et al., 1999; Vogiatzis et al., 2005) and $\mathrm{CO}_{2}$-induced (Romagnoli et al., 2004) hyperpnoea have shown that - independent of the source of respiratory drive - increased ventilatory demands were met by a similar pattern: The endinspiratory increase in chest wall volume was mainly achieved by increasing end-inspiratory volumes of the pulmonary and abdominal rib cage ( $\mathrm{Vrc}, \mathrm{p}$ and $\mathrm{Vrc}, \mathrm{a})$ reflecting the inspiratory rib cage muscle contribution to recruit the inspiratory reserve volume. The end-expiratory decrease in Vcw entirely resulted from an end-expiratory decrease in abdominal volume (Vab), reflecting the abdominal muscle activation to recruit the expiratory reserve volume. This coordinated action of respiratory muscles was suggested to be the ideal strategy to allow the diaphragm to act as a flow generator (Aliverti et al., 1997). Whether volitional normocapnic hyperpnoea $(\mathrm{NH})$ as used during respiratory muscle endurance training shows the same pattern of coordinated muscle action as exercise- and $\mathrm{CO}_{2}$-induced hyperpnoea do, needs to be investigated.

McCool et al. have shown that 5 to 12 min of hyperpnoea specifically elicit diaphragmatic fatigue (McCool et al., 1992) whereas resistive loaded tasks predominantly induce rib cage muscle fatigue (Hershenson et al., 1989; McCool et al., 1992). Studies investigating the influence of specific diaphragmatic fatigue on subsequent exercise- (Verges et al., 2006) and $\mathrm{CO}_{2}$-induced (Laghi et al., 1998; Yan et al., 1993) hyperpnoea showed an increased recruitment of inspiratory rib cage and abdominal muscles compared to the unfatigued state. This implies that, as the diaphragm fatigues, inspiratory rib cage and accessory muscles take over some of the inspiratory work - a mechanism that has also been proposed to occur during 
heavy exercise (Johnson et al., 1993; Mador et al., 1993) and during voluntary hyperpnoea without prior induction of diaphragmatic fatigue (Renggli et al., 2008).

These previous findings suggest that during prolonged hyperpnoea when diaphragmatic fatigue develops (Mador et al., 1996; McCool et al., 1992), a change in muscle recruitment occurs. This might be reflected in a decrease in the relative contribution to tidal volume of the diaphragm and an increase in the relative contribution of the inspiratory rib cage and accessory muscles. Respiratory muscle endurance training could, in turn, reduce the development of diaphragmatic fatigue during exercise and postpone the potential taking over of respiratory work by other respiratory muscles. As a first step, we performed a preliminary study to investigate the effects of prolonged hyperpnoea (at an intensity commonly used for NH-training) on respiratory muscle action by use of OEP.

We hypothesised that during volitional $\mathrm{NH}$ (i) end-inspiratory and end-expiratory compartmental volume changes from quiet breathing would be similar to those observed previously during exercise- or $\mathrm{CO}_{2}$-induced hyperpnoea, (ii) that the development of diaphragmatic fatigue in the course of prolonged $\mathrm{NH}$ would elicit a change in muscle recruitment leading to a change in the relative contributions of the different compartments to tidal volume, namely an increased relative contribution of $\Delta \mathrm{Vrc}, \mathrm{p}$ and decreased relative contributions of $\Delta \mathrm{Vrc}$,a and $\Delta \mathrm{Vab}$, and (iii) that this change in the relative compartmental contribution to tidal volume would be associated with the development of rapid shallow breathing. 


\section{Methods}

\subsection{Subjects}

Thirteen healthy, non-smoking subjects ( 4 men, 9 women; age (mean \pm SD) $29 \pm 5$ y; height $173 \pm 9 \mathrm{~cm}$; body mass $64 \pm 9 \mathrm{~kg}$ ) participated in the study. Subjects were required to refrain from strenuous physical activity for two days before the test days and from any exercise the day before and the day of the tests. Drinking caffeinated beverages on test days prior to testing and food intake $2 \mathrm{~h}$ before testing was not allowed.

After detailed information about the testing procedures, subjects gave their written informed consent. The study was approved by the local ethics committee and performed according to the Declaration of Helsinki.

\subsection{Protocol overview}

Subjects reported to the laboratory on two different occasions, separated by at least $72 \mathrm{~h}$ and scheduled at the same time of day. During the first session, baseline lung function and volitional tests of respiratory muscle strength were assessed and subjects were familiarized with the breathing device for NH. The second test session consisted of lung function and respiratory muscle strength measurements, 5 min of quiet breathing $(\mathrm{QB})$, three vital capacity maneuvers, $1 \mathrm{~h}$ of voluntary $\mathrm{NH}$, and concluded with lung function and respiratory muscle strength measurements immediately after $\mathrm{NH}$ and in the same order as before $\mathrm{NH}$. 


\subsection{Lung function and respiratory muscle strength}

Lung function (vital capacity (VC), forced vital capacity (FVC), forced expiratory volume in $1 \mathrm{~s}\left(\mathrm{FEV}_{1}\right)$, peak expiratory flow rate $(\mathrm{PEF})$, forced inspiratory volume in $1 \mathrm{~s}\left(\mathrm{FIV}_{1}\right)$, peak inspiratory flow rate (PIF), and maximal voluntary ventilation (MVV)) was assessed according to standard procedures (Miller et al., 2005) by use of an ergospirometric device (Quark $b^{2}$, Cosmed, Rome, Italy) with a calibrated turbine for volume measurements.

Respiratory muscle strength (maximal inspiratory mouth pressure (MIP) from residual volume, maximal expiratory mouth pressure (MEP) from total lung capacity, and sniff nasal inspiratory pressure (SNIP) from functional residual capacity) were conducted according to the current statement of ATS/ERS (Green et al., 2002) using a hand held mouth pressure meter (MicroRPM, MicroMedical, Kent, Great Britain). At least five technically satisfactory manoeuvres were conducted and the highest of three values within no more than $5 \%$ variability was selected.

\subsection{Normocapnic hyperpnoea}

$\mathrm{NH}$ was performed at a target ventilation of $70 \%$ of subjects' individual $12 \mathrm{~s}$ MVV with a self-constructed partial rebreathing device. The mouthpiece was connected to a two-way valve (HansRudolph, Shawnee, KS, USA) via the flow-sensor of the Quark $b^{2}$ metabolic cart. The inspiratory port included a valve and at the end of a hose an opening that could be adjusted to alter the amount of fresh air. In the expiratory port, the valve was removed and a hose was connected with a 31 rubber bag and an 'overflow' expiratory one-way valve at the end. Normocapnia was maintained by the experimenter adjusting the inspiratory opening to keep end-tidal $\mathrm{CO}_{2}$ partial pressure $\left(\mathrm{P}_{\mathrm{ET}} \mathrm{CO}_{2}\right)$ constant (assessed by a calibrated infrared 
absorption gas sensor, Quark $b^{2}$ ). Subjects received verbal feedback to keep minute ventilation constant at $70 \%$ MVV. Feedback consisted of telling the subjects to breathe "more" or "less" (without referring to tidal volume or breathing frequency) when they deviated from this target by $\geq 5 \%$ for more than 5 breaths. In addition, subjects were asked every $5 \mathrm{~min}$ to rate their perceived respiratory exertion on a linear scale ranging from 0 (no exertion) to 10 (maximal exertion).

\subsection{Optoelectronic plethysmography}

Chest wall volume changes during QB, vital capacity maneuvers, and volitional NH (all in the standing position) were assessed by OEP (BTS, Milan, Italy). For details see Cala et al. (Cala et al., 1996). Briefly, 89 infrared reflective markers were placed circumferentially on the trunk of the subject. Six infrared cameras (three in front of and three behind the subject) traced the three-dimensional coordinates of these markers at a sampling rate of $60 \mathrm{~Hz}$ in order to compute the thoracoabdominal volumes by use of surface triangulation. The boundaries between the different compartments were set at the level of the xiphoid for the pulmonary and abdominal rib cage and at the lower costal margin for the abdominal rib cage and the abdomen (Figure 1).

\subsection{Data analysis}

OEP data for one minute of QB, the largest vital capacity maneuver, as well as the first 3 min (start), the middle $1 \mathrm{~min}$ (middle), and the last $3 \mathrm{~min}$ (end) of volitional $\mathrm{NH}$ were analyzed.

The following variables were derived from OEP by use of a customized software program (Diamov, designed and developed at the Politecnico di Milano, Dipartimento di 
Bioingegneria, Italy): tidal volume (calculated as the sum of $\Delta \mathrm{Vrc}, \mathrm{p}, \Delta \mathrm{Vrc}, \mathrm{a}$, and $\Delta \mathrm{Vab}$ ), breathing frequency, duty cycle, end-inspiratory and end-expiratory chest wall volumes (all derived from or measured at the zero-flow points), as well as compartmental volumes (given relative to average end-expiratory volume of the respective compartment during $\mathrm{QB}$, which was set to zero), and relative contribution of the different compartments to tidal volume.

In addition, an estimation of mean shortening velocity of the diaphragm $\left(\mathrm{v}_{\mathrm{di}}\right)$ was calculated (Aliverti et al., 2002). According to Aliverti et al., changes in diaphragm fiber length $\left(\mathrm{L}_{\mathrm{di}}\right)$ can be estimated by abdominal displacements, $\Delta \mathrm{Vab}$ (Aliverti et al., 2003). Hence, $\Delta \mathrm{Vab} / \mathrm{T}_{\mathrm{I}}$, where $T_{I}$ represents inspiratory time, is an index of $v_{d i}$ (Aliverti et al., 2002). Similarly, mean shortening velocities of the inspiratory $\left(\mathrm{v}_{\mathrm{rcm}, \mathrm{i}}\right)$ and expiratory rib cage muscles $\left(\mathrm{v}_{\mathrm{rcm}, \mathrm{e}}\right)$ and of the abdominal muscles $\left(\mathrm{v}_{\mathrm{abm}}\right)$ were estimated as $\Delta \mathrm{Vrc}, \mathrm{p} / \mathrm{T}_{\mathrm{I}}, \Delta \mathrm{Vrc}, \mathrm{p} / \mathrm{T}_{\mathrm{E}}$, and $\Delta \mathrm{Vab} / \mathrm{T}_{\mathrm{E}}$, respectively (Aliverti et al., 2002; Duranti et al., 2004), where $\mathrm{T}_{\mathrm{E}}$ is expiratory time.

The Shapiro-Wilk test revealed that not all of the data were normally distributed. To be consistent, all data for QB and the three time points during NH were compared using the nonparametric Friedman test. Where significance was found, differences between time points were assessed by use of the Wilcoxon signed rank test, which was also applied for comparison of lung function and respiratory muscle strength before versus after $\mathrm{NH}$.

Data are presented as mean \pm SD unless otherwise stated. Statistical significance was accepted if $p<0.05$. Statistical analysis was performed using SPSS17.0 (SPSS, Chicago, IL, USA). 


\section{Results}

\subsection{Target ventilation and end-tidal $\mathrm{CO}_{2}$ partial pressure}

Target ventilation at $70 \%$ of the individual MVV (start: $116 \pm 221 \cdot \mathrm{min}^{-1}$, middle: $111 \pm 27$ 1. $\min ^{-1}$, end: $\left.108 \pm 271 \cdot \mathrm{min}^{-1} ; \mathrm{p}=0.441\right)$ and $\mathrm{P}_{\mathrm{ET}} \mathrm{CO}_{2}($ start: $37 \pm 3 \mathrm{mmHg}$, middle: $38 \pm 3$ $\mathrm{mmHg}$, end: $38 \pm 4 \mathrm{mmHg} ; \mathrm{p}=0.178$ ) remained unchanged throughout $1 \mathrm{~h}$ of $\mathrm{NH}$.

\subsection{Lung function and respiratory muscle strength}

In Table 1, data for lung function and respiratory muscle strength are given. Every single parameter was significantly reduced after $\mathrm{NH}$ when compared to before $\mathrm{NH}$.

\subsection{Chest wall volume changes, breathing pattern, and respiratory exertion}

Relative contribution of the different chest wall compartments did not change significantly during NH (Figure 2) while tidal volume decreased and breathing frequency increased continuously in the course of NH (Figure 3). Perception of respiratory exertion also increased significantly in the course of $\mathrm{NH}$ (start: $4.6 \pm 1.7$, middle: $6.7 \pm 1.5$, end: $8.0 \pm 0.7, \mathrm{p}<0.01$ ). At the start of $\mathrm{NH}$, end-inspiratory $\mathrm{Vcw}$ was significantly higher and end-expiratory $\mathrm{Vcw}$ significantly lower compared to QB (Figure 4) and these differences persisted throughout $\mathrm{NH}$, despite a continuous decrease in end-inspiratory $\mathrm{Vcw}$ and tidal volume. The increase in end-inspiratory Vcw above resting values can be attributed to end-inspiratory increases of all three compartments, while the end-expiratory decrease in Vcw is attributable to end- 
expiratory decreases in Vrc,p and Vab. By the end of $\mathrm{NH}$, only end-inspiratory rib cage volumes and end-expiratory Vab remained significantly different from resting values. Of note is that end-inspiratory Vrc,p decreased significantly from start to middle of $\mathrm{NH}$, while endinspiratory Vrc, a and Vab decreased significantly from middle to end of $\mathrm{NH}$.

When comparing male and female subjects, there was no significant sex difference for endinspiratory and end-expiratory volumes, nor for tidal volume, nor for the relative compartmental contribution to tidal volume (data not shown). Only breathing pattern differed between gender: Compared to women, men breathed with a higher breathing frequency (mean: 65 versus $42 \mathrm{~min}^{-1}, \mathrm{p}<0.05$ ) and with a smaller tidal volume relative to vital capacity (mean: 40 versus $59 \%, \mathrm{p}<0.05$ ).

\subsection{Shortening velocities}

Mean calculated shortening velocities of all muscle groups did not change during $\mathrm{NH}$ $(\mathrm{p}>0.05$; Figure 5). 


\section{Discussion}

The present study showed that during volitional $\mathrm{NH}$ chest wall volume changes related to diaphragm and expiratory rib cage muscle action are more pronounced than those previously observed during exercise- and $\mathrm{CO}_{2}$-induced hyperpnoea. During fatiguing $\mathrm{NH}$, the relative contribution of chest wall compartments to tidal volume remained unchanged although endinspiratory $\mathrm{Vcw}$ decreased in the presence of a constant end-expiratory $\mathrm{Vcw}$. In other words, the development of rapid shallow breathing was not associated with a change in compartmental contribution to tidal volume. Therefore, relative compartmental contribution to tidal volume seems to be independent of the breathing pattern even during fatiguing respiratory work.

\subsection{Volitional versus exercise- or $\mathrm{CO}_{2}$-induced, non-volitional hyperpnoea}

While during exercise- and $\mathrm{CO}_{2}$-induced hyperpnoea in healthy, young subjects (Aliverti et al., 1997; Duranti et al., 2004; Romagnoli et al., 2004; Sanna et al., 1999; Vogiatzis et al., 2005), end-inspiratory increases in Vrc,p and Vrc,a and an end-expiratory decrease in Vab are seen, we additionally observed a decrease in end-expiratory Vrc,p, suggesting substantial activity of expiratory rib cage muscles, and an increase in end-inspiratory Vab, likely resulting from more pronounced shortening of the diaphragm.

One possible explanation for the difference between muscle action during volitional $\mathrm{NH}$ and exercise- or $\mathrm{CO}_{2}$-induced hyperpnoea could be the higher ventilatory demand during $\mathrm{NH}$ compared to walking (48 $1 \cdot \mathrm{min}^{-1}$ (Duranti et al., 2004)), cycling $\left(941 \cdot \mathrm{min}^{-1}\right.$ (Vogiatzis et al., 2005)), or $\mathrm{CO}_{2}$-induced hyperpnoea $\left(701 \cdot \mathrm{min}^{-1}\right.$ (Romagnoli et al., 2004)). Another possible 
explanation might be the difference between volitional $\mathrm{NH}$ and brainstem-driven exerciseand $\mathrm{CO}_{2}$-induced hyperpnoea, since the recruitment of the respiratory muscles could be influenced differently by voluntary hyperpnoea.

\subsection{Relative compartmental contribution to changes in chest wall volume}

We expected that inspiratory rib cage muscles would take over some diaphragmatic work in the course of prolonged hyperpnoea. This reasoning was based on previous data showing that volitional hyperpnoea predominantly fatigues the diaphragm (McCool et al., 1992), that diaphragmatic fatigue develops early in the course of prolonged volitional hyperpnoea (Renggli et al., 2008), that the proportion of extradiaphragmatic muscle contribution to inspiration increases in the course of constant-load exercise (Johnson et al., 1993; Mador et al., 1993), and that rib cage muscles take over work of the diaphragm if diaphragmatic fatigue is selectively induced prior to a hyperpnoea-inducing task like exercise or hypercapnia (Laghi et al., 1998; Verges et al., 2006; Yan et al., 1993). However, the relative contribution of the different chest wall compartments did not change in the course of $\mathrm{NH}$ while end-inspiratory chest wall volume decreased and end-expiratory volume was maintained at a level below functional residual capacity. Furthermore, the early and significant decrease in end-inspiratory Vrc,p suggests that inspiratory rib cage muscles fatigue from the start of hyperpnoea. This is supported by the fact that subjects adopted a rapid and shallow breathing pattern and showed an increase in the perception of respiratory exertion, both of which are associated with rib cage muscle fatigue (Verges et al., 2006; Ward et al., 1988). Thus, these findings likely indicate that all inspiratory muscles fatigued simultaneously rather than in succession and that inspiratory rib cage muscles did not take over diaphragmatic work in the course of prolonged NH. Indeed, development of rib cage 
muscle fatigue during hyperpnoea has been observed before (McCool et al., 1992; Renggli et al., 2008). It might be explained by the fact that rib cage as well as abdominal muscles need to develop considerable pressures for the displacement of their compartments in order to let the diaphragm act as the main flow generator (Aliverti et al., 1997).

Differences between the present and previous findings might be explained by methodological differences: i) Subjects in the study of McCool et al. predominantly fatigued the diaphragm during volitional hyperpnoea (McCool et al., 1992) while in the present study, rib cage muscles fatigued as well. Although breathing frequency was higher in McCool's study, it also seems likely that peak flow was higher during the first period where a target peak flow between 5 and $61 \cdot \mathrm{s}^{-1}$ had to be achieved compared to mean peak flows of $4.71 \cdot \mathrm{s}^{-1}$ during the first $3 \mathrm{~min}$ of the present investigation (results not shown). This could have stressed the diaphragm more compared to rib cage muscles. ii) Renggli et al. observed an increasing contribution of rib cage muscles compared to the diaphragm during the course of constantload $\mathrm{NH}$, suggesting that rib cage muscles potentially took over diaphragmatic work (Renggli et al., 2008). However, while Renggli's subjects had to keep their breathing pattern constant, subjects of the present study were free to change, resulting in a continuous decrease in tidal volume with a concomitant increase in breathing frequency. Thus, by reducing tidal volume, our subjects may have adopted a breathing strategy by which they were able to perform $\mathrm{NH}$ for $1 \mathrm{~h}$ compared to the $25 \mathrm{~min}$ (at a similar load) in the above mentioned study. Constant or increasing tidal volume might also be responsible for the observed increasing contribution of the rib cage muscles relative to the diaphragm during intensive cycling exercise with steadily increasing ventilation (Johnson et al., 1993; Mador et al., 1993) and in studies inducing hyperpnoea by increasing inspiratory $\mathrm{CO}_{2}$ (Laghi et al., 1998; Yan et al., 1993). 


\subsection{Shortening velocities, respiratory muscle strength, and breathing pattern}

Muscular fatigue can manifest in a decrease of either maximal force production, or maximal shortening velocity, or both. In our subjects, the decreases in MIP and SNIP as well as MEP after $\mathrm{NH}$ indicate reduced maximal force production of the inspiratory and expiratory muscles, respectively. Also maximal shortening velocities of inspiratory and expiratory muscles were impaired, as indicated by the reductions in $\mathrm{FIV}_{1}, \mathrm{PIF}, \mathrm{FEV}_{1}$, and PEF after NH.

Interestingly, however, submaximal shortening velocities did not decrease in the course of $\mathrm{NH}$, despite substantial changes in both maximal force and velocity generation capacity.

Concerning the diaphragm, the finding of a constant shortening velocity supports its role as the main flow generator, a function which does not seem to be impaired in the course of volitional NH. The constant $\mathrm{v}_{\mathrm{di}}$ might be explained by the observations of Ameredes et al., who report that a loss in force generating capacity plays a more important role than fatigue affecting velocity during repetitive contractions of the rat diaphragm (Ameredes et al., 2000). Indeed, several studies have observed a decrease in the pressure generating capacity of the diaphragm (Laghi et al., 1998; Renggli et al., 2008) long before task failure.

Constant minute ventilation would not necessarily require constant shortening velocities because, for example, inspiratory muscles could lower their velocity of shortening and expiratory muscles could increase theirs with a concomitant increase in duty cycle. However, as shortening velocities and duty cycle did not change in the course of $1 \mathrm{~h}$ of $\mathrm{NH}$, why did subjects then decrease their tidal volume (and increase breathing frequency)? Possibly, shortening velocity and/or relaxation rate of either the diaphragm, rib cage muscles, and/or abdominal muscles could only be maintained with a smaller tidal volume in spite of fatigue. 


\subsection{Critique of methods}

The question might arise as to whether OEP is a valid method to assess changes in chest wall volume. When compared to spirometry, OEP shows high accuracy over a wide range of tidal volumes (Aliverti et al., 2001; Aliverti et al., 2000; Cala et al., 1996; Ferrigno et al., 1994). Limitations of this measurement system, among which the inability to distinguish between changes in gas volume and possible blood shifts and/or gas compression/decompression is certainly the most important one, have been discussed extensively elsewhere (Aliverti et al., 2009; Aliverti et al., 2001; Cala et al., 1996; Kenyon et al., 1997). However, since good agreement between OEP and spirometry has been shown even during exercise (without expiratory flow limitation) (Iandelli et al., 2002; Vogiatzis et al., 2005), i.e. when breathing at high ventilations, we do not believe possible blood shifts and/or gas compression/decompression to influence our results.

We assessed respiratory muscle fatigue by voluntary respiratory maneuvers rather than using intrathoracic pressures and phrenic nerve-stimulation to assess pure contractile fatigue. Indeed, twitch esophageal and gastric pressures would have provided more objective measurements of fatigue, especially regarding the discrimination between diaphragm and inspiratory rib cage muscle fatigue (Similowski et al., 1998). However, we aimed to assure an undisturbed muscle recruitment pattern during $\mathrm{NH}$. While we are aware that voluntary maneuvers may include central fatigue, we consider the development of rapid shallow breathing as an independent index of rib cage muscle fatigue (Verges et al., 2006). Furthermore, contractile fatigue has been shown previously to develop early during fatiguing hyperpnoea at a comparable ventilatory level (Kabitz et al., 2011; Renggli et al., 2008). 


\section{Conclusion}

The constant relative contribution of the different chest wall compartments to tidal volume despite the change towards more rapid and shallow breathing in the course of $1 \mathrm{~h}$ of $\mathrm{NH}$ at constant minute ventilation suggests that the relative compartmental contribution to tidal volume is independent of the breathing pattern and the development of respiratory muscle fatigue. Furthermore, inspiratory muscles seem to fatigue simultaneously rather than in succession and therefore inspiratory rib cage muscles do, most likely, not take over work from the diaphragm. In addition, our results imply an important role of inspiratory rib cage muscles to keep tidal volume high in a flow specific task such as prolonged $\mathrm{NH}$. Therefore, training rib cage muscles in addition to the diaphragm might be essential in reducing the development of respiratory muscle fatigue and in maintaining a high tidal volume to avoid inefficient rapid shallow breathing during exercise. 


\section{Disclosure statement}

Dr. A. Aliverti is a co-inventor of the Optoelectronic Plethysmography system. Its patent rights are held by his Institution, the Politecnico di Milano, Italy. All other authors have no conflict of interest to disclose.

\section{Acknowledgements}

The authors thank Dr. D. Notter for intellectual input and technical support and Dr. R. Briggs for proofreading the manuscript. The study was supported by the Swiss National Science Foundation (SNF grant no. 32-116777). The SNF was not involved in study design, collection, analysis and interpretation of data, writing of the report, and the decision to submit the paper for publication. 


\section{References}

Aliverti, A., Bovio, D., Fullin, I., Dellaca, R.L., Lo Mauro, A., Pedotti, A., Macklem, P.T., 2009. The abdominal circulatory pump. PLoS One 4, e5550.

Aliverti, A., Cala, S.J., Duranti, R., Ferrigno, G., Kenyon, C.M., Pedotti, A., Scano, G., Sliwinski, P., Macklem, P.T., Yan, S., 1997. Human respiratory muscle actions and control during exercise. J. Appl. Physiol. 83, 1256-1269.

Aliverti, A., Dellaca, R., Pelosi, P., Chiumello, D., Gatihnoni, L., Pedoti, A., 2001. Compartmental analysis of breathing in the supine and prone positions by optoelectronic plethysmography. Ann. Biomed. Eng. 29, 60-70.

Aliverti, A., Dellaca, R., Pelosi, P., Chiumello, D., Pedotti, A., Gattinoni, L., 2000. Optoelectronic plethysmography in intensive care patients. Am. J. Respir. Crit. Care Med. 161, 1546-1552.

Aliverti, A., Ghidoli, G., Dellaca, R.L., Pedotti, A., Macklem, P.T., 2003. Chest wall kinematic determinants of diaphragm length by optoelectronic plethysmography and ultrasonography. J. Appl. Physiol. 94, 621-630.

Aliverti, A., Iandelli, I., Duranti, R., Cala, S.J., Kayser, B., Kelly, S., Misuri, G., Pedotti, A., Scano, G., Sliwinski, P., Yan, S., Macklem, P.T., 2002. Respiratory muscle dynamics and control during exercise with externally imposed expiratory flow limitation. J. Appl. Physiol. 92, 1953-1963.

Ameredes, B.T., Zhan, W.Z., Prakash, Y.S., Vandenboom, R., Sieck, G.C., 2000. Power fatigue of the rat diaphragm muscle. J. Appl. Physiol. 89, 2215-2219.

Cala, S.J., Kenyon, C.M., Ferrigno, G., Carnevali, P., Aliverti, A., Pedotti, A., Macklem, P.T., Rochester, D.F., 1996. Chest wall and lung volume estimation by optical reflectance motion analysis. J. Appl. Physiol. 81, 2680-2689. 
Duranti, R., Sanna, A., Romagnoli, I., Nerini, M., Gigliotti, F., Ambrosino, N., Scano, G., 2004. Walking modality affects respiratory muscle action and contribution to respiratory effort. Pflugers Arch. 448, 222-230.

Ferrigno, G., Carnevali, P., Aliverti, A., Molteni, F., Beulcke, G., Pedotti, A., 1994. Threedimensional optical analysis of chest wall motion. J. Appl. Physiol. 77, 1224-1231.

Gigliotti, F., Binazzi, B., Scano, G., 2006. Does training of respiratory muscles affect exercise performance in healthy subjects? Respir. Med. 100, 1117-1120.

Green, M., Road, J., Sieck, G.C., Similowski, T., 2002. ATS/ERS Statement on respiratory muscle testing. Am. J. Respir. Crit. Care Med. 166, 528-547.

Harms, C.A., Babcock, M.A., McClaran, S.R., Pegelow, D.F., Nickele, G.A., Nelson, W.B., Dempsey, J.A., 1997. Respiratory muscle work compromises leg blood flow during maximal exercise. J. Appl. Physiol. 82, 1573-1583.

Hershenson, M.B., Kikuchi, Y., Tzelepis, G.E., McCool, F.D., 1989. Preferential fatigue of the rib cage muscles during inspiratory resistive loaded ventilation. J. Appl. Physiol. 66, $750-754$.

Iandelli, I., Aliverti, A., Kayser, B., Dellaca, R., Cala, S.J., Duranti, R., Kelly, S., Scano, G., Sliwinski, P., Yan, S., Macklem, P.T., Pedotti, A., 2002. Determinants of exercise performance in normal men with externally imposed expiratory flow limitation. J. Appl. Physiol. 92, 1943-1952.

Johnson, B.D., Babcock, M.A., Suman, O.E., Dempsey, J.A., 1993. Exercise-induced diaphragmatic fatigue in healthy humans. J. Physiol. 460, 385-405.

Kabitz, H.J., Walker, D.J., Schwoerer, A., Schlager, D., Walterspacher, S., Storre, J.H., Roecker, K., Windisch, W., Verges, S., Spengler, C., 2011. Biometric Approximation of Diaphragmatic Contractility During Sustained Hyperpnea. Respir. Physiol. Neurobiol. 
Kenyon, C.M., Cala, S.J., Yan, S., Aliverti, A., Scano, G., Duranti, R., Pedotti, A., Macklem, P.T., 1997. Rib cage mechanics during quiet breathing and exercise in humans. J. Appl. Physiol. 83, 1242-1255.

Laghi, F., Topeli, A., Tobin, M.J., 1998. Does resistive loading decrease diaphragmatic contractility before task failure? J. Appl. Physiol. 85, 1103-1112.

Mador, J.M., Rodis, A., Diaz, J., 1996. Diaphragmatic fatigue following voluntary hyperpnea. Am. J. Respir. Crit. Care Med. 154, 63-67.

Mador, M.J., Magalang, U.J., Rodis, A., Kufel, T.J., 1993. Diaphragmatic fatigue after exercise in healthy human subjects. Am. Rev. Respir. Dis. 148, 1571-1575.

McConnell, A.K., Romer, L.M., 2004. Respiratory muscle training in healthy humans: resolving the controversy. Int. J. Sports Med. 25, 284-293.

McCool, F.D., Hershenson, M.B., Tzelepis, G.E., Kikuchi, Y., Leith, D.E., 1992. Effect of fatigue on maximal inspiratory pressure-flow capacity. J. Appl. Physiol. 73, 36-43.

Miller, M.R., Hankinson, J., Brusasco, V., Burgos, F., Casaburi, R., Coates, A., Crapo, R., Enright, P., van der Grinten, C.P., Gustafsson, P., Jensen, R., Johnson, D.C., MacIntyre, N., McKay, R., Navajas, D., Pedersen, O.F., Pellegrino, R., Viegi, G., Wanger, J., 2005. Standardisation of spirometry. Eur. Respir. J. 26, 319-338.

Renggli, A.S., Verges, S., Notter, D.A., Spengler, C.M., 2008. Development of respiratory muscle contractile fatigue in the course of hyperpnoea. Respir. Physiol. Neurobiol. 164, 366-372.

Romagnoli, I., Gigliotti, F., Lanini, B., Bianchi, R., Soldani, N., Nerini, M., Duranti, R., Scano, G., 2004. Chest wall kinematics and respiratory muscle coordinated action during hypercapnia in healthy males. Eur. J. Appl. Physiol. 91, 525-533.

Romer, L.M., McConnell, A.K., Jones, D.A., 2002. Inspiratory muscle fatigue in trained cyclists: effects of inspiratory muscle training. Med. Sci. Sports Exerc. 34, 785-792. 
Sanna, A., Bertoli, F., Misuri, G., Gigliotti, F., Iandelli, I., Mancini, M., Duranti, R., Ambrosino, N., Scano, G., 1999. Chest wall kinematics and respiratory muscle action in walking healthy humans. J. Appl. Physiol. 87, 938-946.

Sheel, A.W., 2002. Respiratory muscle training in healthy individuals: physiological rationale and implications for exercise performance. Sports Med. 32, 567-581.

Similowski, T., Straus, C., Attali, V., Duguet, A., Derenne, J.P., 1998. Cervical magnetic stimulation as a method to discriminate between diaphragm and rib cage muscle fatigue. J. Appl. Physiol. 84, 1692-1700.

St Croix, C.M., Morgan, B.J., Wetter, T.J., Dempsey, J.A., 2000. Fatiguing inspiratory muscle work causes reflex sympathetic activation in humans. J. Physiol. 529 Pt 2, 493504.

Verges, S., Boutellier, U., Spengler, C.M., 2008. Effect of respiratory muscle endurance training on respiratory sensations, respiratory control and exercise performance: a 15year experience. Respir. Physiol. Neurobiol. 161, 16-22.

Verges, S., Lenherr, O., Haner, A.C., Schulz, C., Spengler, C.M., 2007. Increased fatigue resistance of respiratory muscles during exercise after respiratory muscle endurance training. Am. J. Physiol. 292, R1246-1253.

Verges, S., Notter, D., Spengler, C.M., 2006. Influence of diaphragm and rib cage muscle fatigue on breathing during endurance exercise. Respir. Physiol. Neurobiol. 154, 431442.

Vogiatzis, I., Aliverti, A., Golemati, S., Georgiadou, O., Lomauro, A., Kosmas, E., Kastanakis, E., Roussos, C., 2005. Respiratory kinematics by optoelectronic plethysmography during exercise in men and women. Eur. J. Appl. Physiol. 93, 581587. 
Ward, M.E., Eidelman, D., Stubbing, D.G., Bellemare, F., Macklem, P.T., 1988. Respiratory sensation and pattern of respiratory muscle activation during diaphragm fatigue. J. Appl. Physiol. 65, 2181-2189.

Ward, M.E., Ward, J.W., Macklem, P.T., 1992. Analysis of human chest wall motion using a two-compartment rib cage model. J. Appl. Physiol. 72, 1338-1347.

Wylegala, J.A., Pendergast, D.R., Gosselin, L.E., Warkander, D.E., Lundgren, C.E., 2007. Respiratory muscle training improves swimming endurance in divers. Eur. J. Appl. Physiol. 99, 393-404.

Yan, S., Lichros, I., Zakynthinos, S., Macklem, P.T., 1993. Effect of diaphragmatic fatigue on control of respiratory muscles and ventilation during $\mathrm{CO} 2$ rebreathing. J. Appl. Physiol. 75, 1364-1370. 


\section{FIGURE LEGENDS}

Fig. 1. Optoelectronic plethysmography: Marker positions on the trunk and the three chest wall compartments (pulmonary rib cage, abdominal rib cage, and abdomen). The horizontal marker line at the level of the xiphoid denotes the boundary between the pulmonary and abdominal rib cage and the marker line at the lower costal margin separates the abdominal rib cage from the abdomen (modified from www.btsbioengineering.com).

Fig. 2. Mean compartmental contributions of the pulmonary rib cage ( $\Delta \mathrm{Vrc}, \mathrm{p})$, the abdominal rib cage $(\Delta \mathrm{Vrc}, \mathrm{a})$, and the abdomen $(\Delta \mathrm{Vab})$ to tidal volume during quiet breathing $(\mathrm{QB})$, at the start, middle, and end of $1 \mathrm{~h}$ of volitional normocapnic hyperpnoea (NH). TLC, total lung capacity; RV, residual volume. No significant changes were observed.

Fig. 3. Time course of tidal volume $\left(V_{T}\right)$, breathing frequency $\left(f_{R}\right)$, and duty cycle (DC), during $1 \mathrm{~h}$ of volitional normocapnic hyperpnoea. Values are means \pm SE. Significances are shown for changes between time points. $* \mathrm{p}<0.05, * * \mathrm{p}<0.01$. 
Fig. 4. Chest wall (Vcw) and compartmental volumes (pulmonary rib cage, Vrc,p, abdominal rib cage, Vrc,a, and abdomen, Vab) during quiet breathing (QB) and at the start, middle, and end of $1 \mathrm{~h}$ of volitional normocapnic hyperpnoea $(\mathrm{NH})$. Note the different scale for the y-axis for Vcw. Dashed line, end-expiratory volume during QB, which was set to 0. Solid grey lines, end-inspiratory and end-expiratory volumes of the largest vital capacity (VC) maneuvers. Values are means \pm SE. Significances are shown for changes during NH (above and below the VC lines) and differences to QB (above or below the end-inspiratory or endexpiratory points). ${ }^{*} \mathrm{p}<0.05, * * \mathrm{p}<0.01$.

Fig. 5. Relative changes in estimated velocities of shortening of the diaphragm $\left(v_{\mathrm{di}}\right)$, the inspiratory rib cage muscles $\left(\mathrm{v}_{\mathrm{rcp}, \mathrm{i}}\right)$, the expiratory rib cage muscles $\left(\mathrm{v}_{\mathrm{rcp}, \mathrm{e}}\right)$, and the abdominal muscles $\left(\mathrm{v}_{\mathrm{abm}}\right)$ in the course of $1 \mathrm{~h}$ of normocapnic hyperpnea compared to start $(=100 \%)$. Values are means \pm SE. There are no significant differences between time points, neither for the estimated shortening velocities nor for the changes in shortening velocities. 


\section{Table 1}

Lung function and respiratory muscle strength before and after normocapnic hyperpnoea

\begin{tabular}{|c|c|c|c|c|c|c|c|}
\hline \multirow{2}{*}{$\begin{array}{l}\text { Lung function } \\
\end{array}$} & \multicolumn{4}{|c|}{ before $\mathrm{NH}$} & \multirow{2}{*}{\multicolumn{3}{|c|}{$\begin{array}{l}\text { after NH } \\
\text { absolute }\end{array}$}} \\
\hline & \multicolumn{2}{|c|}{$\%$ predicted } & \multicolumn{2}{|c|}{ absolute } & & & \\
\hline $\mathrm{FVC}[1]$ & 117 & \pm 13 & $5.0 \pm$ & $=0.9$ & 4.6 & \pm & $1.1 * *$ \\
\hline $\mathrm{FEV}_{1}[1]$ & 112 & \pm 12 & $4.1 \pm$ & $=0.6$ & 3.8 & \pm & $0.7 * *$ \\
\hline $\operatorname{PEF}\left[1 \cdot \mathrm{s}^{-1}\right]$ & 113 & $\pm \quad 22$ & $9.2 \pm$ & $=2.3$ & 8.3 & \pm & $2.1 * *$ \\
\hline FIV $1[1]$ & 118 & \pm 14 & $4.3 \pm$ & $=0.7$ & 4.0 & \pm & $0.8 * *$ \\
\hline $\operatorname{PIF}\left[1 \cdot \mathrm{s}^{-1}\right]$ & & na & $7.0 \pm$ & $=1.8$ & 6.3 & \pm & $2.0 * *$ \\
\hline $\operatorname{MVV}\left[1 \cdot \min ^{-1}\right]$ & 129 & \pm 18 & $166.8 \pm$ & $=36.1$ & & na & \\
\hline Respiratory mus & & & & & & & \\
\hline $\mathrm{MIP}\left[\mathrm{cmH}_{2} \mathrm{O}\right]$ & 130 & \pm 26 & $110 \pm$ & $=17$ & 94 & \pm & $19 * *$ \\
\hline $\mathrm{MEP}\left[\mathrm{cmH}_{2} \mathrm{O}\right]$ & 132 & \pm 40 & $148 \pm$ & $=51$ & 126 & \pm & $40 * *$ \\
\hline $\mathrm{SNIP}\left[\mathrm{cmH}_{2} \mathrm{O}\right]$ & 69 & \pm 39 & $64 \pm$ & $=35$ & 53 & \pm & $35 *$ \\
\hline
\end{tabular}

Values are means \pm SD. NH, volitional normocapnic hyperpnoea; FVC, forced vital capacity; $\mathrm{FEV}_{1}$, forced expiratory volume in $1 \mathrm{~s} ; \mathrm{PEF}$, peak expiratory flow rate; $\mathrm{FIV}_{1}$, forced inspiratory volume in $1 \mathrm{~s}$; PIF, peak inspiratory flow rate; MVV, maximal voluntary ventilation; MIP, maximal inspiratory mouth pressure; MEP, maximal expiratory mouth pressure; SNIP, sniff nasal inspiratory pressure $(n=12)$; na, not available. Reference values are from (Quanjer et al., 1993; Uldry and Fitting, 1995; Wilson et al., 1984). Significances are indicated for differences between absolute values before versus after $\mathrm{NH} * \mathrm{p}<0.05$, $* * \mathrm{p}<0.01$ 
Figure 1

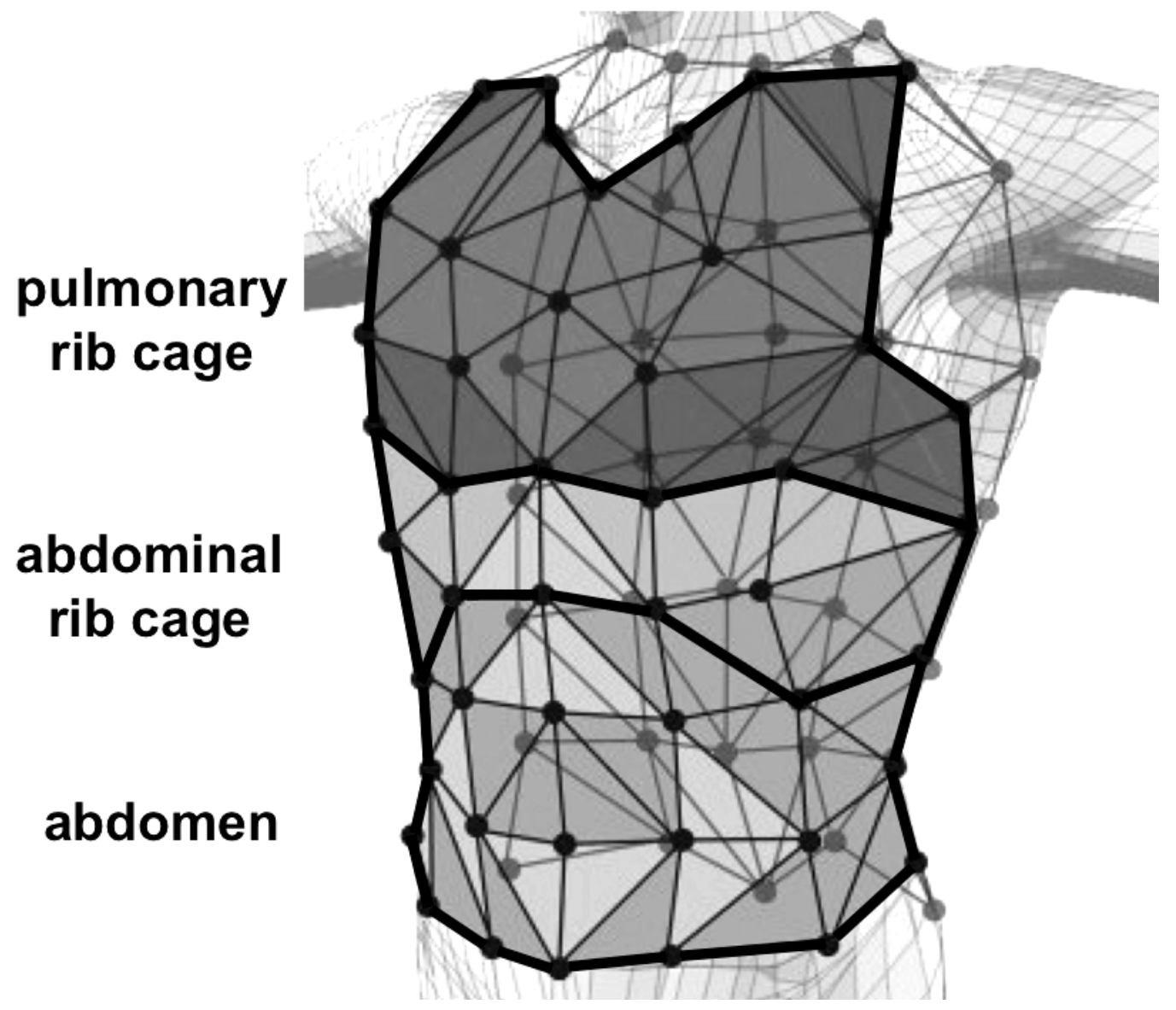


Figure 2

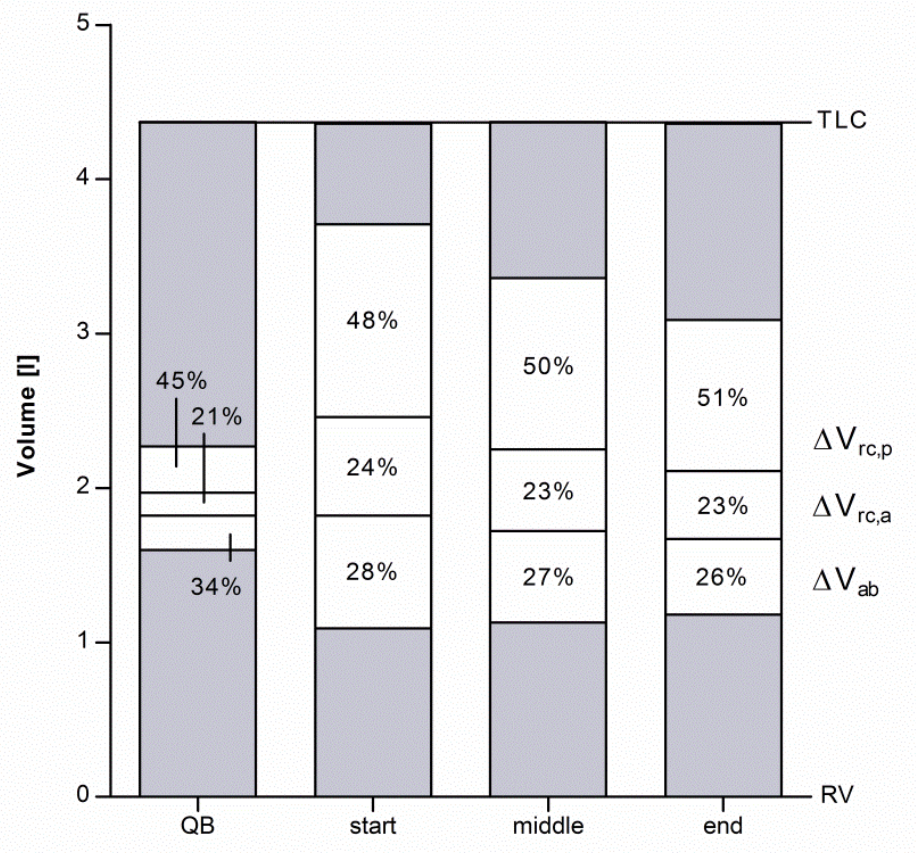


Figure 3
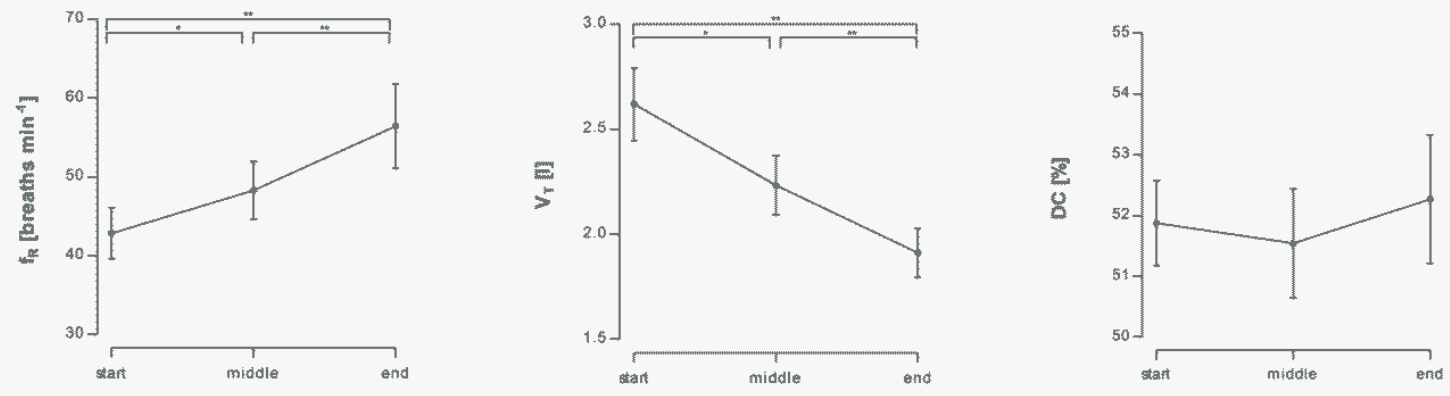
Figure 4
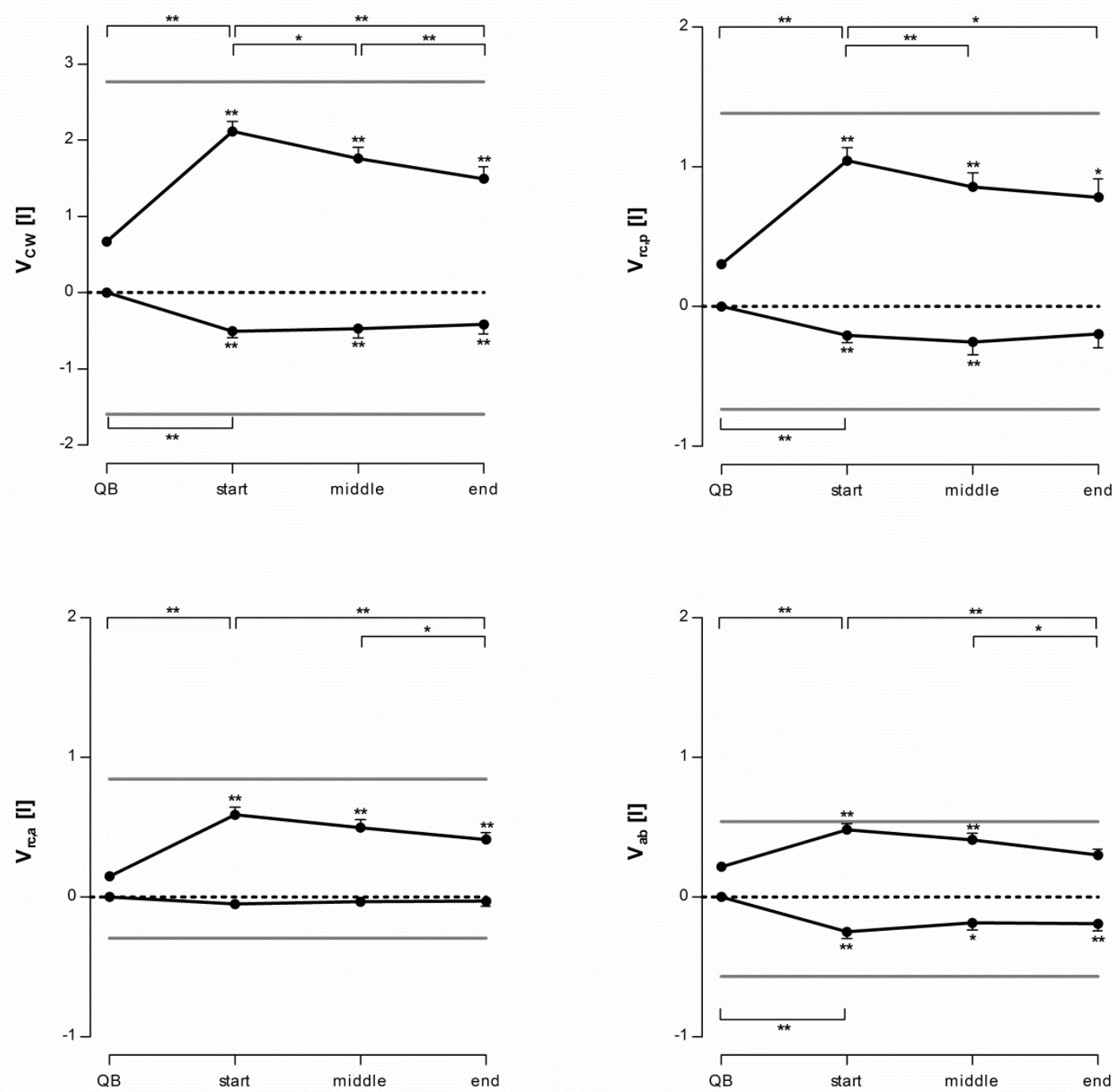
Figure 5

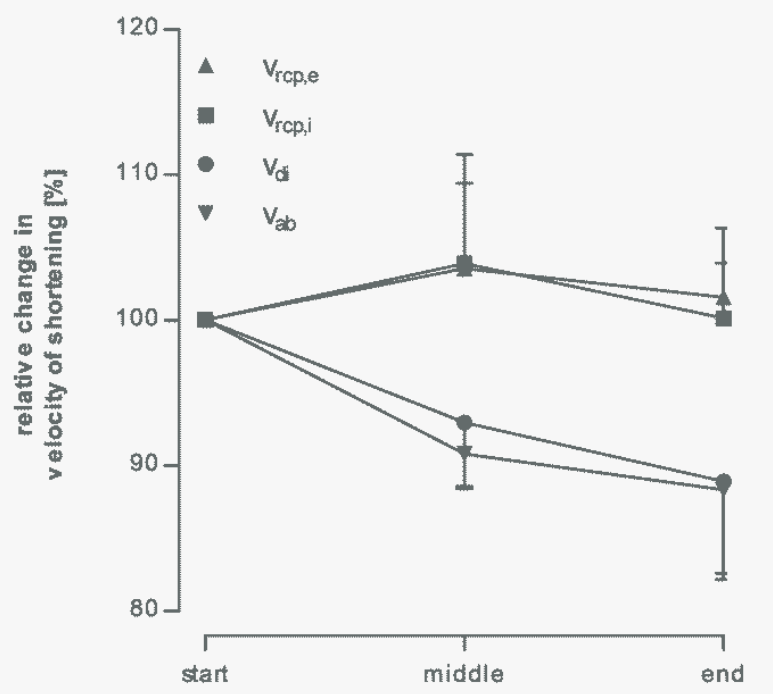

